\title{
Rose hip supplementation increases energy expenditure and induces browning of white adipose tissue
}

\author{
Michele Cavalera*, Ulrika Axling, Karin Berger and Cecilia Holm
}

\begin{abstract}
Background: Overweight and obesity are widespread chronic disorders defined as excessive fat accumulation, and are major risk factors for several chronic diseases including type 2 diabetes, coronary heart disease, high blood pressure and fatty liver. Changes in lifestyle such as increased physical activity and a healthy diet can be crucial tools for treating obesity. Intake of rose hip, the fruit of several plants belonging to the Rosaceae family, has been shown to reduce body fat mass and prevent body weight gain. Thus, the aim of the study was to elucidate potential mechanisms through which rose hip inhibit diet-induced obesity.
\end{abstract}

Methods: C57BL/6 J mice were fed a high fat diet with (RH) or without (CTR) rose hip supplementation for three months. In vivo indirect calorimetry was monitored, as well as gene expression and protein levels of different adipose depots.

Results: Although no differences in energy intake were found compared to the CTR group, RH prevented body weight gain and lowered blood glucose, insulin and cholesterol levels. Indirect calorimetry showed that RH-fed mice have significantly higher EE during the dark phase, despite comparable voluntary activity. Moreover, when challenged with treadmill running, $\mathrm{RH}$-fed mice exhibited higher metabolic rate. Therefore, we hypothesized that $\mathrm{RH}$ could stimulate the brown adipose tissue (BAT) thermogenic capacity or may induce browning of the white adipose tissue (WAT). Compared to the CTR group, gene expression and protein levels of some brown and "brite" markers, together with genes able to promote brown adipocyte differentiation and thermogenesis (such as ucp 1, tbx 15, bmp7, and cidea), as well as phosphorylation of AMPK, was increased in WAT (but not in BAT) of RH-fed mice.

Conclusions: Taken together these results indicate that dietary rose hip prevents body weight gain by increasing whole body EE and inducing browning of WAT. Thus, it has potential therapeutic implication for treatment of obesity and related metabolic disorders.

Keywords: Obesity, Diet, Browning, Energy expenditure, Rose hip

\section{Background}

Obesity is a condition that leads to premature death due to several comorbidities, such as cardiovascular disease [1], type 2 diabetes [2], hypertension [3] and cancer [4, 5]. Adipose tissue consists of two functionally and morphologically distinct tissue types, the WAT and BAT [6]. One of the main roles of the unilocular WAT is the storage of triglycerides and release of fatty acids and adipocytokines, while the multilocular BAT also dissipates energy in the form of heat through the constitutively expressed UCP1 $[7,8]$. Another sub-type of adipocytes with thermogenic

\footnotetext{
* Correspondence: michele.cavalera@med.lu.se

Department of Experimental Medical Science, Lund University, Lund, Sweden
}

capacity can appear within the WAT in response to different stimuli [9]. These cells have been named "brite" (brown in white), "beige", "inducible" or "recruitable", and attain features typical of the BAT such as high mitochondrial content, multilocular lipid droplets and the ability to express BAT-specific genes [9-12]. Since the discovery of BAT also being present in adult humans [13-17], increasing its thermogenic capacity or inducing the conversion of white into beige fat could be a therapeutic strategy for obesity, diabetes and metabolic disorders [8].

Many factors like drugs, cold exposure, adrenergic stimulation and exercise are able to induce browning of the white fat $[8,11,18]$. Some dietary components can 
also affect energy homeostasis. For instance resveratrol [19], curcumin [20] or conjugated linoleic acids [21] have been shown to reduce adiposity and induce brownlike adipocyte in WAT.

Rose hip (RH) is the fruit of several plants of the genus Rosa, belonging to the Rosaceae family, and it is rich in ascorbic acid [22], phenolic compounds [23] and carotenoids [24]. It exerts anti-obesity, anti-inflammatory and anti-oxidative effects both in vivo and in vitro [25-30], and has beneficial and pain-relieving properties in subjects with arthritis [31-34]. Obesity results from an imbalance between energy intake (EI) and energy expenditure (EE), and the aim of this study was to elucidate the mechanisms underlying the anti-obesity effects of rose hip.

\section{Methods}

\section{Experimental animal procedures}

Eight-week old male C57BL/6 J mice were purchased from Taconic, Denmark. The animals were maintained in a temperature-controlled room $\left(22{ }^{\circ} \mathrm{C}\right)$ with a $12: 12 \mathrm{~h}$ light:dark cycle with free access to food and water. After one week of acclimatization, mice were randomly divided in two groups $(n=12)$ and fed a control HFD (CTR) or a HFD supplemented with rose hip (RH) for 3 months. The study was approved by the Local Animal Ethics Committee (Lund, Sweden).

\section{Diets}

The two experimental diets contained 45 energy \% from fat (Research diets, New Brunswick, NJ, USA) (Table 1). Rose hip powder was obtained from Orkla ASA, (Oslo, Norway) and analyzed by Eurofins Food \& Agro Testing (Sweden). Based on its composition (Table 2), the macronutrient content was balanced in the two diets.

\section{Glucose tolerance test}

An intraperitoneal glucose tolerance test (IPGTT) was performed on 6-hr-fasted mice by injecting $2 \mathrm{~g} / \mathrm{Kg}$ of D-(+)-glucose (SIGMA-Aldrich, St. Louis, MO) followed by blood sampling from the saphenous vein in heparincoated tubes at 0, 30, 60 and $120 \mathrm{~min}$. Blood samples were centrifuged and plasma was collected and analyzed with Infinity $^{\text {ma }}$-Glucose (Fisher Diagnostic, Middletown - VA) according to the manufacturer's instructions.

\section{Insulin tolerance test}

An intraperitoneal insulin tolerance test (IPITT) was performed on 4-hr-fasted mice by injecting $0.75 \mathrm{U} / \mathrm{kg}$ of insulin (Actrapid ${ }^{\circledR}$, Novo Nordisk, Denmark). Blood samples were collected at 0, 15, 30 and $60 \mathrm{~min}$ and blood glucose levels were determined with Accu-check Aviva (Roche Diagnostic Gmbh, Germany).
Table 1 Diet composition

\begin{tabular}{lll}
\hline Ingredients (g) & CTR & RH \\
\hline Casein & 200 & 191.3 \\
L-Cysteine & 3 & 3 \\
Corn Starch & 50 & - \\
Maltodextrin 10 & 100 & 83 \\
Glucose & 21.6 & - \\
Fructose & 23.4 & - \\
Sucrose & 175 & 148.1 \\
Cellulose & 97.4 & - \\
Soybean Oil & 25 & 16.2 \\
Lard & 177.5 & 177.5 \\
Mineral Mix & 10 & 10 \\
Dicalcium phosphate & 13 & 13 \\
Calcium Carbonate & 5.5 & 5.5 \\
Potassium Citrate & 16.5 & 16.5 \\
Vitamin Mix & 10 & 10 \\
Choline Bitartrate & 2 & 2 \\
Rose hip & - & 295 \\
Total (g) & 929.9 & 971.1 \\
Protein (Kcal \%) & 18 & 18 \\
Carbohydrates (Kcal \%) & 37 & 37 \\
Fat (Kcal \%) & 45 & 45 \\
Kcal/g & 4.4 & \\
\hline & & \\
\hline & &
\end{tabular}

\section{Plasma analysis}

At the end of the study blood was withdrawn by orbital puncture and collected in heparin-coated tubes from 10-hr fasted isofluorane-anesthetized mice. The blood was immediately centrifuged and plasma was collected, snap-frozen and stored at $-80{ }^{\circ} \mathrm{C}$. To assess plasma insulin, total cholesterol and triglycerides levels, Insulin ELISA assays

Table 2 Rose hip powder analysis (per $100 \mathrm{~g}$ )

\begin{tabular}{ll}
\hline Moisture content & $8.53 \mathrm{~g} \pm 10 \%$ \\
Ash & $5.76 \mathrm{~g} \pm 10 \%$ \\
Fat & $2.98 \mathrm{~g} \pm 10 \%$ \\
Protein & $2.62 \mathrm{~g} \pm 10 \%$ \\
Carbohydrates (calculated) & $47.1 \mathrm{~g}$ \\
Fiber & $33.0 \mathrm{~g} \pm 15 \%$ \\
Fructose & $7.93 \mathrm{~g} \pm 15 \%$ \\
Glucose & $7.32 \mathrm{~g} \pm 15 \%$ \\
Sucrose & $9.11 \mathrm{~g} \pm 15 \%$ \\
Saturated fatty acids & $27.7 \%$ \\
Monounsaturated fatty acids & $9.7 \%$ \\
Polyunsaturated fatty acids & $51.8 \%$ \\
Ascorbic acid & $440 \mathrm{mg} \pm 10 \%$ \\
\hline
\end{tabular}


(Mercodia, Sweden), Infinity ${ }^{\mathrm{mm}}$-Cholesterol and Infinity ${ }^{\mathrm{mm}}$ Triglycerides assays (Fisher Diagnostic, Middletown - VA) were used according to the manufacturer's instructions.

\section{Indirect gas calorimetry and behavioral monitoring}

Whole-body energy metabolism, food and water intake as well as voluntary locomotor and wheel activity were measured with PhenoMaster/LabMaster Home cage System (TSE-systems, Germany). Mice were weighed and acclimatized for two days prior to the experiments. All parameters were recorded every $15 \mathrm{~min}$ for $24 \mathrm{~h}$. Two $24-\mathrm{h}$ experiments were carried out and averaged for each mouse.

\section{Treadmill and indirect calorimetry measurements}

The experiment was performed with a CaloTreadmill (TSE systems - Germany) set at a $20 \%$ inclination after a four-day training. EE, oxygen and carbon dioxide fractions were continuously monitored and the respiratory exchange ratio (RER) was calculated. Protocol run: after placing the mice inside the treadmill, the speed slightly increased from $0-14 \mathrm{~m} / \mathrm{min}$ for $5 \mathrm{~min}$, then from 14$18 \mathrm{~m} / \mathrm{min}$ for $15 \mathrm{~min}$ followed by constant running at $18 \mathrm{~m} / \mathrm{min}$ for $28 \mathrm{~min}$. After that, the speed decreased from 18 to $0 \mathrm{~m} / \mathrm{min}$ in $1 \mathrm{~min}$. Exhaustion was defined as the inability to continue regular running.

\section{Oxygen consumption in WAT and BAT}

The Clark oxygen sensor electrode (DW1, Hansatech Instruments, Norfolk, UK) was mounted in a chamber according to the manufacturer's instructions and connected to a computer-operated control unit to register the cellular respiration (Oxygraph software, Hansatech). Prior to the experiment, the oxygen electrode was calibrated in Krebs Ringer HEPES (KRH) buffer (25 mM HEPES pH 7.5, $120 \mathrm{mM} \mathrm{NaCl}, 4.74 \mathrm{mM} \mathrm{CaCl}_{2}, 2 \mathrm{mM}$ glucose, $200 \mu \mathrm{M}$ adenosine, $1 \%$ fatty acid free BSA) at $37{ }^{\circ} \mathrm{C}$. A 2-point calibration was performed between the oxygen levels of air-saturated buffer and zero oxygen buffer. Perigonadal WAT and interscapular BAT were excised and immediately placed in KRH buffer. For this experiment a separate set of female mice were used. These mice were fed CTR and RH diets for 17 weeks. The diets were similar to the ones described above except for that they contained 41 energy \% fat and that the ascorbic acid present in the $\mathrm{RH}$ was compensated for in the CTR diet. The tissues were analyzed for oxygen consumption within $2 \mathrm{~h}$ after excision. KRH buffer (500 $\mathrm{\mu l}$ /experiment) was pre-warmed at $37{ }^{\circ} \mathrm{C}$ in the oxygraph chamber and the measurement was started by establishing a stable background. A piece of WAT (62 \pm $7 \mathrm{mg})$ or BAT $(15 \pm 4 \mathrm{mg})$ was minced 30 times with a pair of scissors and thereafter added to the KRH buffer in the chamber. The samples were continuously stirred with a magnetic stirrer and the lid of the chamber was adjusted to the sample volume. The oxygen consumption was measured during the first $6 \mathrm{~min}$ after addition of the tissue and expressed as $\mathrm{nmol} / \mathrm{min} / \mathrm{mg}$ tissue (after subtraction of background).

\section{Bomb calorimetry}

The gross energy content in feces was determined with a bomb calorimeter (Parr Instrument Company - USA). Feces was collected from single-caged mice, freeze-dried for $24 \mathrm{~h}$, and a pellet of approximately $1 \mathrm{~g}$ was made and burnt into the 1108P Oxygen Bomb (Parr Instrument Company - USA) following the manufacturer's instruction.

\section{RNA preparation and real-time quantitative PCR}

Total RNA was isolated from the tissue using Qiazol lysis reagent (Quiagen Sciences, USA). Two $\mu \mathrm{g}$ of RNA were treated with DNase I (DNase I amplification grade; Invitrogen, CA) and then reversely transcribed using random hexamers (Amersham Biosciences, NJ) and SuperScript II reverse transcriptase (Invitrogen, CA). Quantitative real-time polymerase chain reactions were performed using ABI PRISM 7900 System with TaqMan primers bmp7 (Mm00432102_m1), ppargc1a (Mm01208835_m1), fgf21 (Mm00840165_g1), elovl3 (Mm00468164_m1), rps29 (Mm02342448_gH), tbp (Mm01277042_m1), cidea (Mm00432554_m1), car4 (Mm00483021_m1), tfam (Mm00447485_m1), nrf1 (Mm01135606_m1) and reagents (Applied Biosystems, CA); Qiagen SYBR green primers were Prdm16 (QT00148127), tbx15 (QT00148127), zic1 (QT00173502), tcf21 (QT00100688), ucp1 (QT00097300), cpt1 (QT00172564) and tbp (QT00198443). Each reaction was performed in duplicate and results were normalized to the geometric average of two internal controls (Rps29 and Tbp).

\section{Western blotting}

Approximately $50 \mathrm{mg}$ of tissue were homogenized in lysis buffer (50 mM Tris- $\mathrm{HCl}, \mathrm{pH} 7.5,1 \mathrm{mM}$ EGTA, $1 \mathrm{mM}$ EDTA, 1\% NP40, $1 \mathrm{mM}$ Na-orthovanadate, $40 \mathrm{mM}$ $\mathrm{NaF}, 4 \mathrm{mM}$ Na-pyrophosphate, $0.27 \mathrm{M}$ sucrose, $1 \mathrm{mM}$ DTT, $20 \mu \mathrm{g} / \mathrm{ml}$ leupeptin, $10 \mu \mathrm{g} / \mathrm{ml}$ antipain and $1 \mu \mathrm{g} / \mathrm{ml}$ pepstatin) and subsequently centrifuged at 12,000 $\mathrm{g}$ for $20 \mathrm{~min}$ at $4{ }^{\circ} \mathrm{C}$. Protein concentration of the supernatant was determined using BCA-assay (Pierce) and $20 \mu \mathrm{g}$ of proteins were resolved on NuPAGE 4-12\% Bis-Tris Gel (Life technologies - Carlsbad, CA) and electroblotted to nitrocellulose membranes (Amersham, GE Healthcare UK). Primary antibodies used were: Cidea (Abin1858406 Antibodies online), beta-actin (A5441 - Sigma), pAMPK (CST2535 - Cell Signaling), AMPK (CST2603 - Cell Signaling), PGC1 $\alpha$ (Ab54481 - Abcam). Secondary antibodies were: sheep anti-mouse (NA931V - GE Healthcare) and goat anti-rabbit (31460 - Thermo Fisher). 


\section{Statistical analysis}

Results are presented as means \pm SD. Statistical analysis was performed with Graph-Pad Prism 6 using unpaired Student's $t$-test and two-way ANOVA followed by Tukey's post-hoc test for the treadmill data set. Values of $p<0.05$ were considered statistically significant.

\section{Results}

\section{$\mathrm{RH}$ supplementation prevents weight gain and exerts} anti-diabetic effects

At the end of the study, mice fed $\mathrm{RH}$ showed reduced body weight (Fig. 1a) and fasting glucose levels (Fig. 1b), despite similar EI between the two groups (Fig. 1c). An IPGTT revealed that $\mathrm{RH}$-fed mice have increased glucose disposal (Fig. 1d) while no differences were found after an IPITT (Fig. 1e). Compared to the CTR group, RH supplementation markedly reduced plasma total-cholesterol and insulin levels (Fig. 1f-g). Triglycerides levels were comparable between the two groups (Fig 1h).
$\mathrm{RH}$ feeding increases $\mathrm{EE}, \mathrm{VO}_{2}$ and $\mathrm{VCO}_{2}$

24-h calorimetric cages experiments showed no differences in locomotor activity, wheel running or EE (Fig. 2a-c) between the two groups of mice. However, when considering the dark phase only, $\mathrm{RH}$-fed animals displayed again similar locomotor (Fig. 2d) and wheel activity (Fig. 2e), but showed markedly higher EE (Fig. 2f), suggesting that the increased EE was not attributed to hyperactivity. Furthermore, analysis of the feces revealed a significantly higher energy content following RH feeding (Fig. 2g). Additionally, a previous oxygen consumption experiment performed on ex vivo WAT and BAT from female mice indicated that mitochondrial respiration was increased upon $\mathrm{RH}$-feeding (Fig. 3a and b), corroborating the new in vivo results.

\section{RH supplementation increases metabolic rate during treadmill exercise}

Since physical exercise increases EE $[35,36]$ and activates the browning program [18], we challenged the two groups of mice with treadmill running. Again, indirect
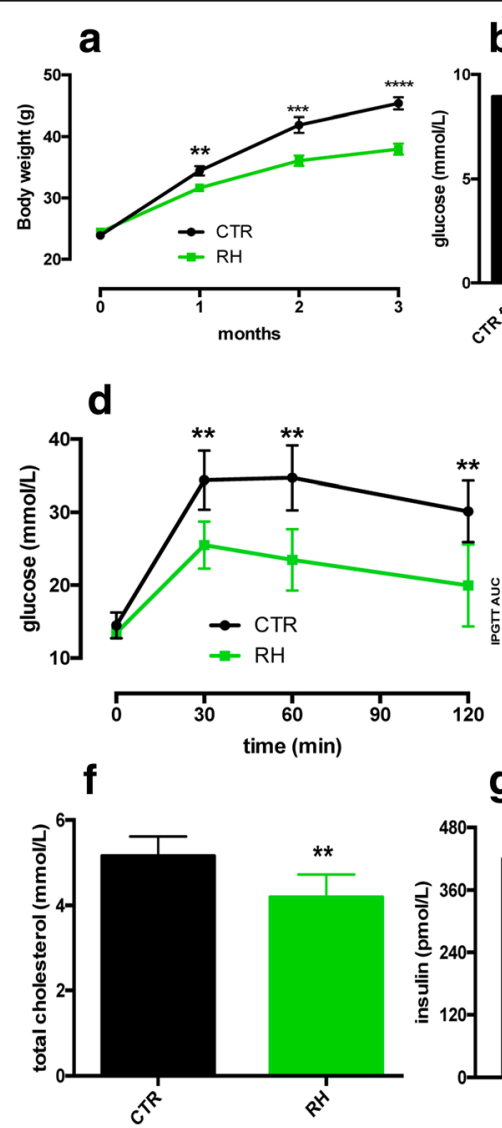

g

\section{b}

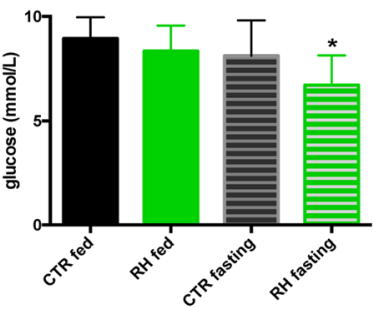

e
C

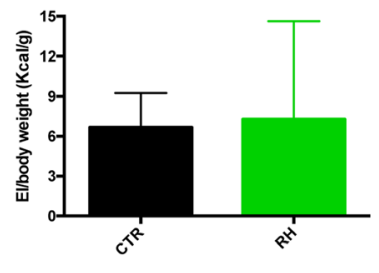

e
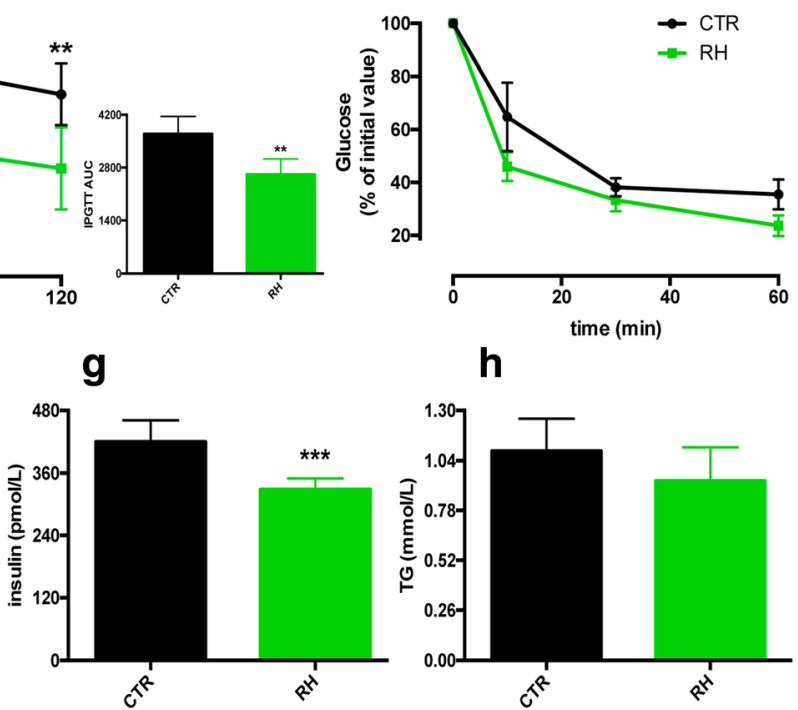

Fig. 1 Dietary RH intake prevents diet-induced obesity and reduces glucose and insulin levels. a RH feeding prevented body weight gain and $\mathbf{b}$ ) reduced blood glucose levels $(n=16)$ during high-fat feeding. $\mathbf{c}$ No differences were found in energy intake between the two groups of mice $(n=10)$. d Dietary RH improved glucose disposal after an IPGTT $(n=6)$ but e) had no effect upon an IPITT $(n=6)$. $\mathbf{f}-\mathbf{h}$ RH effects on plasma cholesterol, insulin and TG levels $(n=6)$. ${ }^{*} P<0.05 ;{ }^{* *} p<0.005 ;{ }^{* *} p<0.001$ and ${ }^{* * *} p<0.0001$ vs CTR 

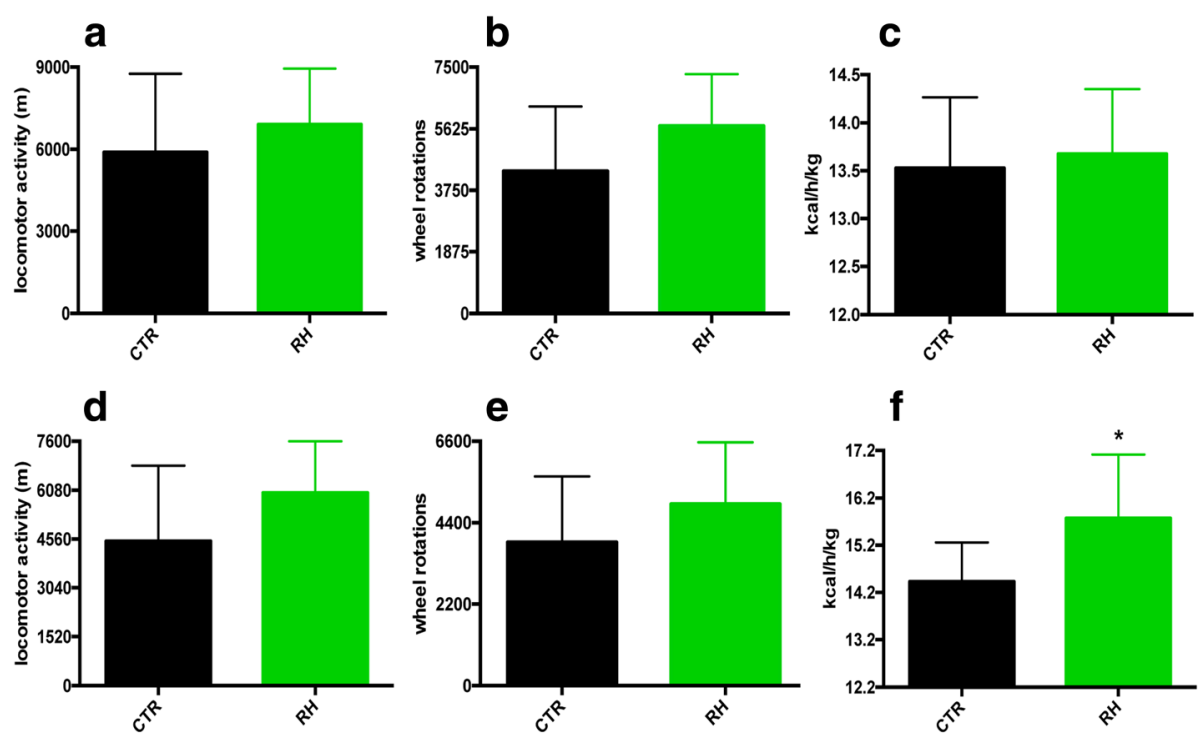

e
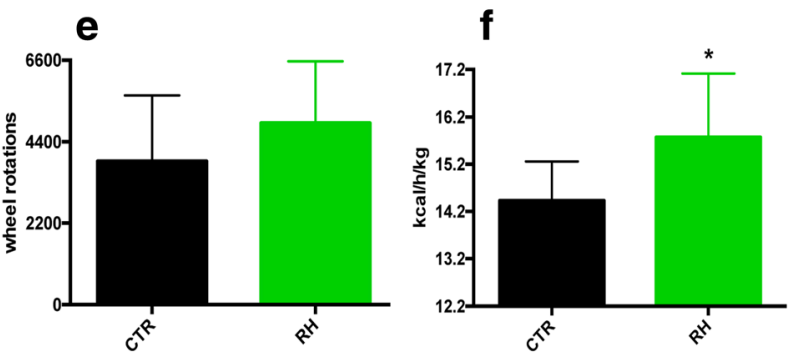

\section{g}

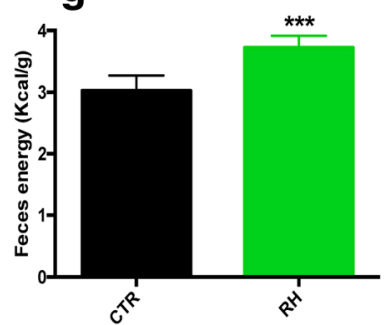

Fig. 2 RH intake increases EE during the dark cycle. a-c Locomotor activity, wheel rotations and EE during 24-h measurements, and $\mathbf{d}$-f) during the 12-h dark phase only $(n=8-9)$. $\mathbf{g}$ Increased fecal energy content upon RH feeding $(n=6)$. ${ }^{*} p<0.05$ and ${ }^{* *} p<0.001$ vs CTR

calorimetry showed that RH-fed mice had considerably higher EE (Fig. 4a) and $\mathrm{VO}_{2}$ (Fig. 4b), while no differences were found in the RER (4c). Interestingly, one mouse of the $\mathrm{RH}$-group was not able to conclude the run, while another one completed the test but reached the bottom of the treadmill a few times before immediately restarting the running. All the CTR-mice concluded the test without any problem.

\section{RH feeding upregulates ucp1 and other BAT and brite markers in WAT}

In order to investigate if dietary $\mathrm{RH}$ is able to stimulate BAT thermogenic activity, we analyzed the expression of selected genes of the interscapular brown adipose depot. Compared to the CTR group, no differences were found in the expression of $u c p 1$ or any of the other genes analyzed (Fig. 5a). Next, we examined the expression of BAT- and brite-markers in the subcutaneous inguinal WAT (scWAT). In this fat depot, $u c p 1$ was markedly upregulated by $\mathrm{RH}$, as well as $b m p 7, t b \times 15$ and cidea (Fig. 5b). Furthermore, among markers of mitochondrial oxidation, $c p t 1$ was significantly increased (Fig. $5 \mathrm{~b}$ ). The expression of zic1, a typical BAT marker, was undetected in both groups (Fig. 5b). Western blotting analysis revealed that dietary RH markedly upregulated CIDEA
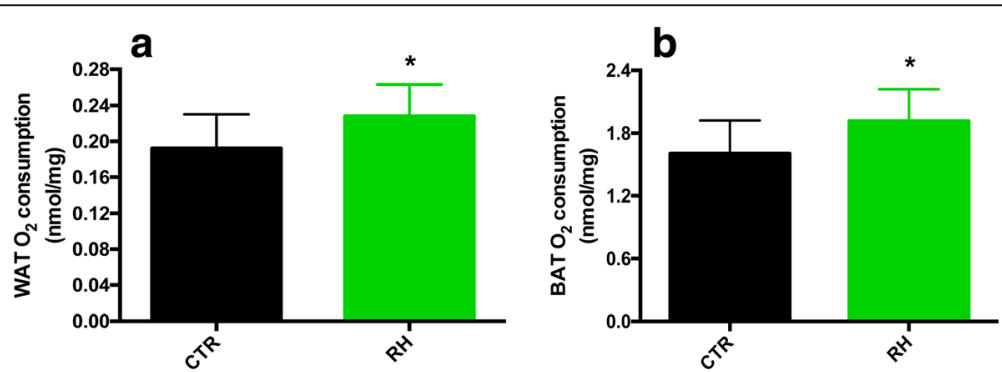

Fig. 3 Increased oxygen consumption in WAT and BAT obtained from RH-fed mice. a WAT and b) BAT $\mathrm{O}_{2}$ consumption $(n=9-10)$ was increased upon $\mathrm{RH}$ feeding. ${ }^{*} P<0.05$ vs $C T R$ 

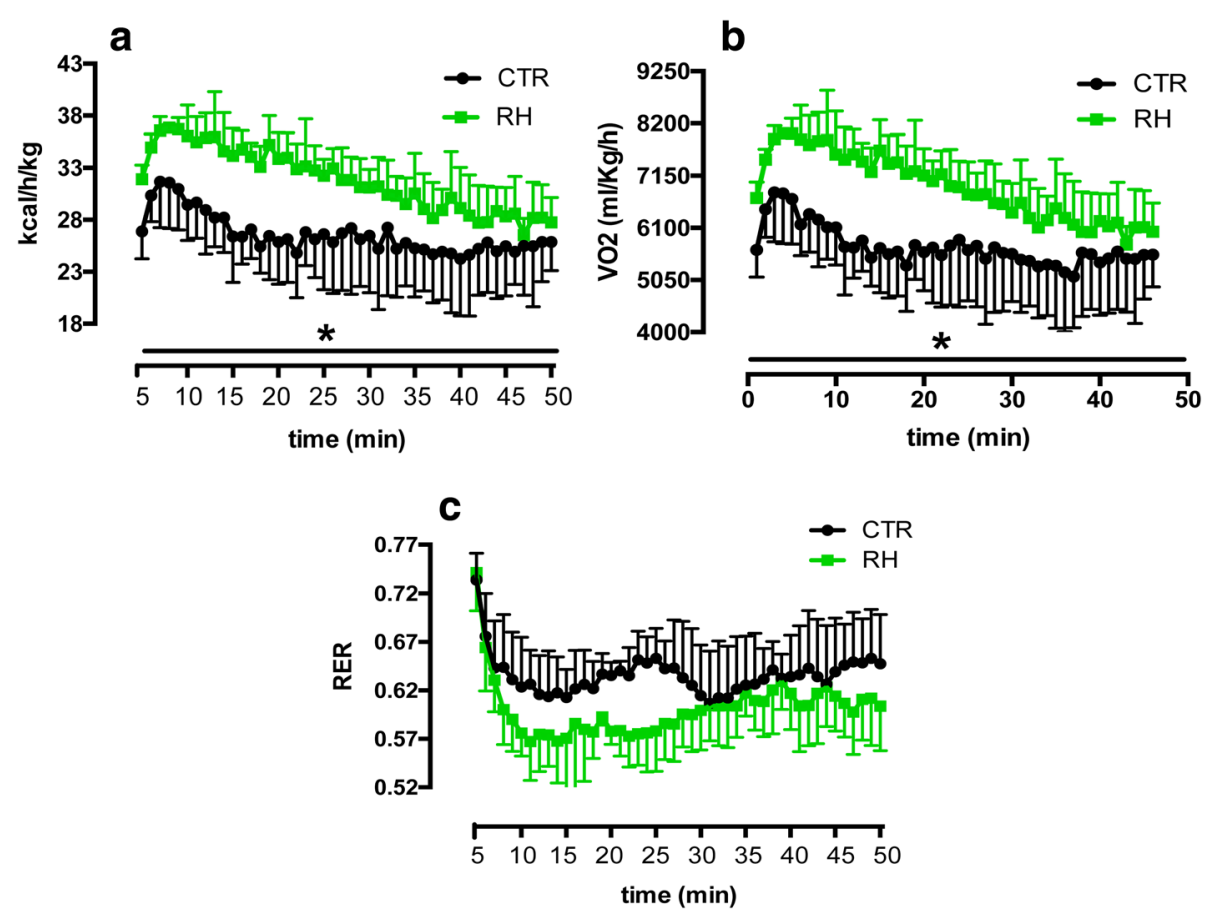

Fig. $4 \mathrm{RH}$ supplementation increases metabolic rate during treadmill exercise. $\mathrm{RH}$ feeding led to a significantly increased $\mathrm{EE}(\mathbf{a})$ and $\mathrm{VO}_{2}(\mathbf{b})$, while RER (c) was comparable between the two groups during treadmill running $(n=5)$. ${ }^{*} P<0.05$ vs CTR

and increased the phosphorylation of AMPK (Fig. 5c), while the tendency for increased PGC1 $\alpha$ levels did not reach significant differences (Fig. 5c).

\section{Discussion}

Obesity develops from an unbalance of energy homeostasis when EI exceeds EE. It represents a major risk factor for the development of type 2 diabetes, dyslipidemia, cardiovascular disease and several other conditions. Our previous studies indicate that $\mathrm{RH}$ is able to prevent weight gain [26], so we aimed at investigating the mechanisms through which $\mathrm{RH}$ exerts these effects by challenging C57BL/6 J mice with a HFD supplemented with RH.

Compared to the CTR group, RH supplementation prevented body weight gain and reduced glucose, insulin and cholesterol levels even though the two groups showed similar EI. We then used calorimetric cages to measure in vivo indirect-gas calorimetry. Despite no differences were found during the 24-h measurement, $\mathrm{RH}$-fed mice displayed higher EE during the dark phase, while spontaneous wheel and locomotor activities were comparable between the two groups. Bomb calorimetry analysis showed that feces of $\mathrm{RH}$-fed mice had higher energy content compared to the CTR group, indicating that $\mathrm{RH}$ decreases intestinal energy absorption. This effect most likely contributes to the anti-obesity effect of RH. In addition, mice fed RH exhibited higher metabolic rate also during intense physical exercise. The fact that one mouse of the RH-group ended the treadmill test before the end of the experiment, and another one was close to, but did not reach exhaustion, could reflect an insufficient delivery of adipose tissue-derived fatty acids to skeletal muscle, as a result of higher mitochondrial uncoupling capacity due to browning.

Quantitative PCR analysis revealed no gene expression differences in the interscapular BAT between the two groups of animals, but showed that dietary RH strikingly upregulates $u c p 1$ and other genes such as $b m p 7, t b x 15$, cidea and cpt1 in the scWAT, indicating attainment of brown-like characteristics of the subcutaneous adipocytes. BMP7 is a bone morphogenic protein known for promoting brown adipogenesis and increasing the expression of UCP1; it also induces mitochondrial biogenesis through p38 mitogen-activated protein (MAP) kinase and PGC1dependent pathways [37]. As a matter of fact, bmp7-null mice show complete absence of UCP1, while overexpression of BMP7 increased brown fat mass and EE and reduced weight gain $[37,38]$. Included among the genes upregulated by $\mathrm{RH}$ feeding is $t b \times 15$, a transcription factor that is required for adipogenesis in BAT and inguinal WAT, but not in epididymal WAT [39]. It has been reported that $t b x 15$ knockdown reduced the expression of PGC1 $\alpha$ and UCP1, but had no effects on white epididymal adipocytes, suggesting that TBX15 may be essential for the development of adipogenic and thermogenic programs in fat depots capable of developing brown 


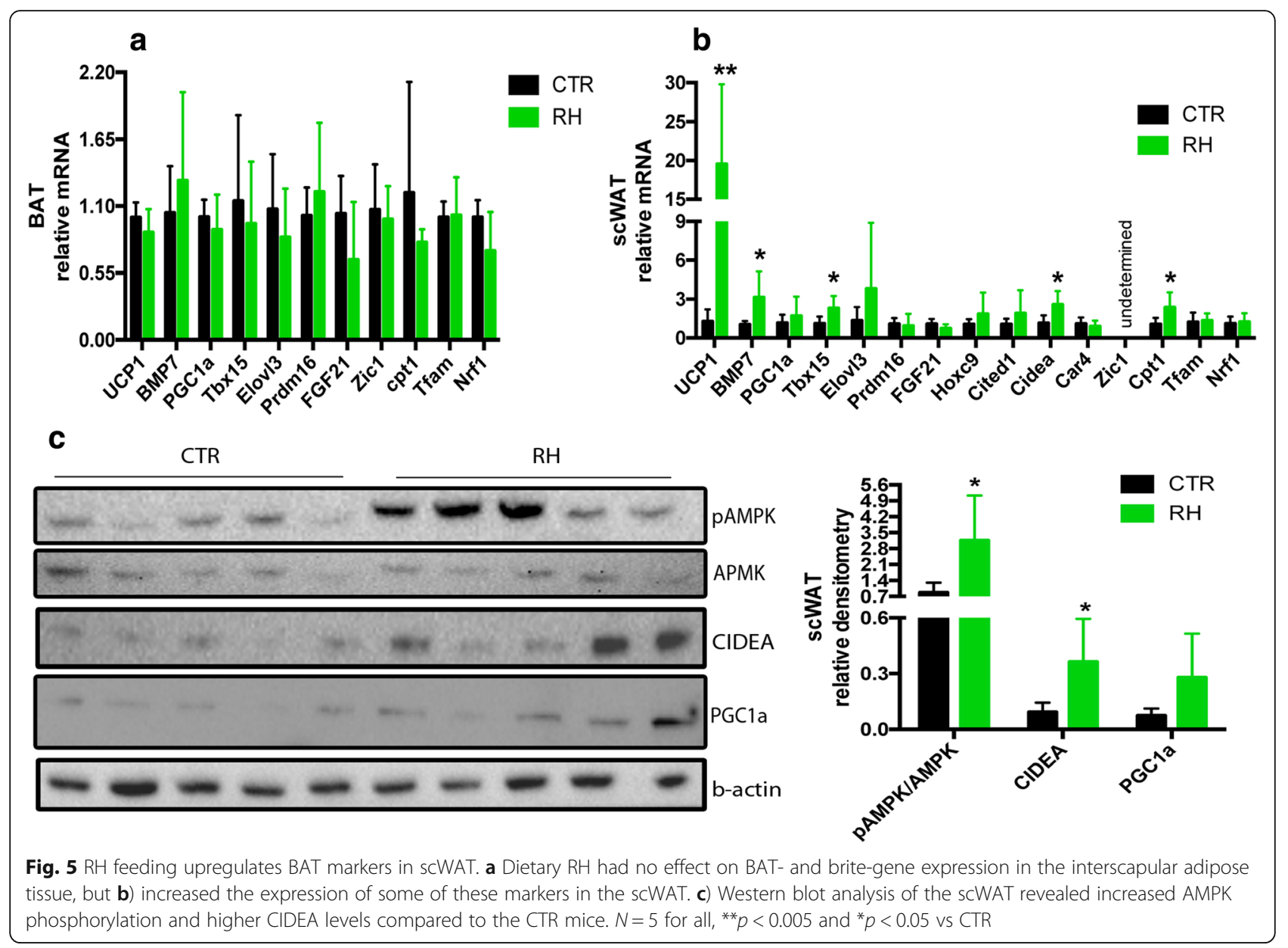

adipocyte features [40]. CIDEA is a multifunctional protein involved in apoptosis and transcriptional regulation. Its cold-induced increment in WAT suggests that CIDEA could be an important effector during the browning process. Indeed, in ucp 1 knockout mice, cidea is dramatically induced in WAT by cold exposure, indicating that it participates in cold acclimatization mechanisms independent of UCP1 [41]. However, gene expression of other "brite" markers such as hoxc 9, fgf 21 , cited 1 and car4 did not change upon $\mathrm{RH}$ feeding.

Together with CIDEA protein levels, phosphorylation of AMPK was also elevated in the RH group. Much of the interest in AMPK generated in the past years is due to the observation that its activity is reduced in most genetic models of obesity [42]. Very recently, Wang and coworkers demonstrated that resveratrol induces brownlike adipocyte formation in white fat through activation of AMPK [19]. AMPK can also phosphorylate PGC1 $\alpha$ to increase mitochondrial biogenesis [43], and another study showed that AMPK is essential for brown adipocyte differentiation and browning of WAT [44]. Thus, the increased AMPK phosphorylation observed upon RH feeding may be an important mechanism for reducing obesity and increasing $\mathrm{EE}$, but it requires further investigation.

\section{Conclusions}

In the present study we identify two possible mechanisms whereby RH may exert anti-obesity effects. First, dietary intake of RH induces browning of scWAT through upregulation of some BAT markers and increased phosphorylation of AMPK. Second, dietary intake of RH appears to decrease intestinal energy absorption. Thus, $\mathrm{RH}$ intake exerts anti-obesity through effects on both EE and EI. Confirmatory experiments in human subjects as well as complementary mechanistic studies are required in order to grant $\mathrm{RH}$ a "brite" future as a dietary supplement to prevent and treat obesity and related metabolic disorders.

\section{Abbreviations}

BAT: brown adipose tissue; EE: energy expenditure; El: Energy intake; IPGTT: intraperitoneal glucose tolerance test; IPITT: intraperitoneal insulin tolerance test; RER: respiratory exchange ratio; RH: rose hip; sc

WAT: subcutaneous white adipose tissue; WAT: white adipose tissue

\section{Acknowledgements}

We thank Anders Högberg at Orkla ASA (Oslo - Norway) for providing the rose hip powder. 


\section{Funding}

This study was supported by the Swedish Research Council (project grant 11284 to C.H.); Linnaeus Centre of Excellence grant 349-2006-237; EXODIAB Strategic Research Grant 2009-1039; the Swedish Diabetes association, Sydvästra Skånes Diabetesförening and the following foundations: Albert Påhlsson, Dr. P. Håkansson, Fredrik and Ingrid Thuring, Crafoord and Sigurd and Elsa Goljes Minne.

\section{Availability of data and materials}

All dataset are presented in the main paper.

\section{Authors' contribution}

$M C$, UA and KB performed the experiments. MC, UA, KB and $\mathrm{CH}$ analyzed the data, wrote the manuscript and contributed to discussion. All authors reviewed the manuscript.

\section{Competing interests}

The authors declare that they have no competing interests.

\section{Consent for publication}

Not applicable.

\section{Ethics approval and consent to participate}

Rodent studies were approved by the Local Animal Ethics Committee (Lund, Sweden).

Received: 13 September 2016 Accepted: 29 November 2016 Published online: 06 December 2016

\section{References}

1. Van Gaal LF, Mertens IL, De Block CE. Mechanisms linking obesity with cardiovascular disease. Nature. 2006:444:875-80.

2. Kahn SE, Hull RL, Utzschneider KM. Mechanisms linking obesity to insulin resistance and type 2 diabetes. Nature. 2006:444:840-6.

3. Sjostrom L, Lindroos AK, Peltonen M, Torgerson J, Bouchard C, Carlsson B, Dahlgren S, Larsson B, Narbro K, Sjostrom CD, et al. Lifestyle, diabetes, and cardiovascular risk factors 10 years after bariatric surgery. N Engl J Med. 2004;351:2683-93.

4. Bianchini F, Kaaks R, Vainio H. Overweight, obesity, and cancer risk. Lancet Oncol. 2002;3:565-74.

5. Bianchini $F$, Kaaks R, Vainio $H$. Weight control and physical activity in cancer prevention. Obes Rev. 2002;3:5-8.

6. Servera M, Lopez N, Serra F, Palou A. Expression of "brown-in-white" adipocyte biomarkers shows gender differences and the influence of early dietary exposure. Genes Nutr. 2014:9:372

7. Scime A, Grenier G, Huh MS, Gillespie MA, Bevilacqua L, Harper ME, Rudnicki MA. $\mathrm{Rb}$ and $\mathrm{p} 107$ regulate preadipocyte differentiation into white versus brown fat through repression of PGC-1alpha. Cell Metab. 2005;2:283-95.

8. Townsend $\mathrm{KL}$, Tseng $\mathrm{YH}$. Brown fat fuel utilization and thermogenesis. Trends Endocrinol Metab. 2014;25:168-77.

9. Harms M, Seale P. Brown and beige fat: development, function and therapeutic potential. Nat Med. 2013;19:1252-63.

10. Ishibashi J, Seale P. Medicine. Beige can be slimming. Science. 2010;328:1113-4.

11. Nedergaard J, Cannon B. The browning of white adipose tissue: some burning issues. Cell Metab. 2014;20:396-407.

12. Petrovic N, Walden TB, Shabalina IG, Timmons JA, Cannon B, Nedergaard J. Chronic peroxisome proliferator-activated receptor gamma (PPARgamma) activation of epididymally derived white adipocyte cultures reveals a population of thermogenically competent, UCP1-containing adipocytes molecularly distinct from classic brown adipocytes. J Biol Chem. 2010;285:7153-64.

13. Cypess AM, Lehman S, Williams G, Tal I, Rodman D, Goldfine AB, Kuo FC, Palmer EL, Tseng YH, Doria A, et al. Identification and importance of brown adipose tissue in adult humans. N Engl J Med. 2009:360:1509-17.

14. Nedergaard J, Bengtsson T, Cannon B. Unexpected evidence for active brown adipose tissue in adult humans. Am J Physiol Endocrinol Metab. 2007;293:E444-452.

15. Zingaretti MC, Crosta F, Vitali A, Guerrieri M, Frontini A, Cannon B, Nedergaard J, Cinti S. The presence of UCP1 demonstrates that metabolically active adipose tissue in the neck of adult humans truly represents brown adipose tissue. FASEB J. 2009;23:3113-20.
16. Virtanen KA, Lidell ME, Orava J, Heglind M, Westergren R, Niemi T, Taittonen M, Laine J, Savisto NJ, Enerback S, Nuutila P. Functional brown adipose tissue in healthy adults. N Engl J Med. 2009;360:1518-25.

17. van Marken Lichtenbelt WD, Vanhommerig JW, Smulders NM, Drossaerts JM, Kemerink GJ, Bouvy ND, Schrauwen P, Teule GJ. Cold-activated brown adipose tissue in healthy men. N Engl J Med. 2009;360:1500-8.

18. Stanford KI, Middelbeek RJ, Goodyear LJ. Exercise Effects on White Adipose Tissue: Beiging and Metabolic Adaptations. Diabetes. 2015;64:2361-8.

19. Wang S, Liang X, Yang Q, Fu X, Rogers CJ, Zhu M, Rodgers BD, Jiang Q, Dodson MV, Du M. Resveratrol induces brown-like adipocyte formation in white fat through activation of AMP-activated protein kinase (AMPK) alpha1. Int J Obes (Lond). 2015;39:967-76.

20. Lone J, Choi JH, Kim SW, Yun JW. Curcumin induces brown fat-like phenotype in 3 T3-L1 and primary white adipocytes. J Nutr Biochem. 2016:27:193-202.

21. Shen W, Chuang CC, Martinez K, Reid T, Brown JM, Xi L, Hixson L, Hopkins R, Starnes J, Mclntosh M. Conjugated linoleic acid reduces adiposity and increases markers of browning and inflammation in white adipose tissue of mice. J Lipid Res. 2013:54:909-22.

22. Stralsjo L, Alklint C, Olsson ME, Sjoholm I. Total folate content and retention in rosehips (Rosa ssp.) after drying. J Agric Food Chem. 2003:51:4291-5.

23. Daels-Rakotoarison DA, Gressier B, Trotin F, Brunet C, Luyckx M, Dine T, Bailleul F, Cazin M, Cazin JC. Effects of Rosa canina fruit extract on neutrophil respiratory burst. Phytother Res. 2002;16:157-61.

24. Hodisan T, Socaciu C, Ropan I, Neamtu G. Carotenoid composition of Rosa canina fruits determined by thin-layer chromatography and high-performance liquid chromatography. J Pharm Biomed Anal. 1997;16:521-8.

25. Lattanzio F, Greco E, Carretta D, Cenvellati R, Govoni P, Speroni E. In vivo antiinflammatory effect of Rosa canina L. extract. J Ethnopharmacol. 2011;137:880-5.

26. Andersson U, Henriksson E, Strom K, Alenfall J, Goransson O, Holm C. Rose hip exerts antidiabetic effects via a mechanism involving downregulation of the hepatic lipogenic program. Am J Physiol Endocrinol Metab. 2011;300:E111-121.

27. Andersson U, Berger $K$, Hogberg A, Landin-Olsson M, Holm C. Effects of rose hip intake on risk markers of type 2 diabetes and cardiovascular disease: a randomized, double-blind, cross-over investigation in obese persons. Eur J Clin Nutr. 2012;66:585-90.

28. Nagatomo A, Nishida N, Matsuura Y, Shibata N. Rosehip Extract Inhibits Lipid Accumulation in White Adipose Tissue by Suppressing the Expression of Peroxisome Proliferator-activated Receptor Gamma. Prev Nutr Food Sci. 2013;18:85-91

29. Nagatomo A, Nishida N, Fukuhara I, Noro A, Kozai Y, Sato H, Matsuura Y. Daily intake of rosehip extract decreases abdominal visceral fat in preobese subjects: a randomized, double-blind, placebo-controlled clinical trial. Diabetes Metab Syndr Obes. 2015;8:147-56.

30. Widen C, Ekholm A, Coleman MD, Renvert S, Rumpunen K. Erythrocyte antioxidant protection of rose hips (Rosa spp.). Oxid Med Cell Longev. 2012;2012:621579.

31. Christensen R, Bartels EM, Altman RD, Astrup A, Bliddal H. Does the hip powder of Rosa canina (rosehip) reduce pain in osteoarthritis patients?-a meta-analysis of randomized controlled trials. Osteoarthritis Cartilage. 2008;16:965-72

32. Warholm O, Skaar S, Hedman E, Molmen HM, Eik L. The Effects of a Standardized Herbal Remedy Made from a Subtype of Rosa canina in Patients with Osteoarthritis: A Double-Blind, Randomized, Placebo-Controlled Clinical Trial. Curr Ther Res Clin Exp. 2003;64:21-31.

33. Willich SN, Rossnagel K, Roll S, Wagner A, Mune O, Erlendson J, Kharazmi A, Sorensen $\mathrm{H}$, Winther $\mathrm{K}$. Rose hip herbal remedy in patients with rheumatoid arthritis - a randomised controlled trial. Phytomedicine. 2010;17:87-93.

34. Winther K, Apel K, Thamsborg G. A powder made from seeds and shells of a rose-hip subspecies (Rosa canina) reduces symptoms of knee and hip osteoarthritis: a randomized, double-blind, placebo-controlled clinical trial. Scand J Rheumatol. 2005;34:302-8.

35. Wu MV, Bikopoulos G, Hung S, Ceddia RB. Thermogenic capacity is antagonistically regulated in classical brown and white subcutaneous fat depots by high fat diet and endurance training in rats: impact on whole-body energy expenditure. J Biol Chem. 2014;289:34129-40.

36. Stanford Kl, Middelbeek RJ, Townsend KL, Lee MY, Takahashi H, So K, Hitchcox KM, Markan KR, Hellbach K, Hirshman MF, et al. A novel role for subcutaneous adipose tissue in exercise-induced improvements in glucose homeostasis. Diabetes. 2015;64:2002-14. 
37. Tseng YH, Kokkotou E, Schulz TJ, Huang TL, Winnay JN, Taniguchi CM, Tran TT, Suzuki R, Espinoza DO, Yamamoto Y, et al. New role of bone morphogenetic protein 7 in brown adipogenesis and energy expenditure. Nature. 2008:454:1000-4.

38. Boon MR, van den Berg SA, Wang Y, van den Bossche J, Karkampouna S, Bauwens M, De Saint-Hubert M, van der Horst G, Vukicevic S, de Winther MP, et al. BMP7 activates brown adipose tissue and reduces diet-induced obesity only at subthermoneutrality. PLoS One. 2013;8, e74083.

39. Lo KA, Sun L. Turning WAT into BAT: a review on regulators controlling the browning of white adipocytes. Biosci Rep. 2013;33.

40. Gburcik V, Cawthorn WP, Nedergaard J, Timmons JA, Cannon B. An essential role for Tbx15 in the differentiation of brown and "brite" but not white adipocytes. Am J Physiol Endocrinol Metab. 2012;303:E1053-1060.

41. Barneda D, Frontini A, Cinti S, Christian M. Dynamic changes in lipid droplet-associated proteins in the "browning" of white adipose tissues. Biochim Biophys Acta. 1831;2013:924-33.

42. Steinberg GR, Kemp BE. AMPK in Health and Disease. Physiol Rev. 2009;89:1025-78

43. Jager S, Handschin C, St-Pierre J, Spiegelman BM. AMP-activated protein kinase (AMPK) action in skeletal muscle via direct phosphorylation of PGC-1alpha. Proc Natl Acad Sci U S A. 2007;104:12017-22.

44. Vila-Bedmar R, Lorenzo M, Fernandez-Veledo S. Adenosine 5'-monophosphate-activated protein kinase-mammalian target of rapamycin cross talk regulates brown adipocyte differentiation. Endocrinology. 2010;151:980-92.

\section{Submit your next manuscript to BioMed Central and we will help you at every step:}

- We accept pre-submission inquiries

- Our selector tool helps you to find the most relevant journal

- We provide round the clock customer support

- Convenient online submission

- Thorough peer review

- Inclusion in PubMed and all major indexing services

- Maximum visibility for your research

Submit your manuscript at www.biomedcentral.com/submit

C) Biomed Central 